\title{
Neurose narcísica em tempos de isolamento
}

\author{
Narcissistic neurosis in times of isolation
}

\section{Elisangela Muria', Vitoria Justin dos Santos'2, Henrique Borba Bittencourt ${ }^{3}$, Gabriel Licoski dos Santos ${ }^{4}$ e Kamily Ramos Moro}

Resumo: Dentre as principais estruturas psíquicas da psicanálise, a estrutura neurótica se constituí com complexidade e se difere a partir dos diferentes destinos dado a experiência traumática vivida pelo indivíduo, bem como os diferentes níveis de cada neurose. Pensando as características da estrutura neurótica, surgiu a necessidade de repensar a neurose narcísica de forma mais minuciosa, especialmente pelo fato desta ter sido pautada sobre a realidade vivida no contexto global atual. Contexto este que ilustra um momento de pandemia, no qual cada sujeito vive a experiência de estar frente à possibilidade de contágio e às consequências sofridas por ele a partir deste ambiente. Esta realidade conduziu a interrogativa, como podemos, na atualidade, pensar a estrutura neurótica, como uma estrutura hermética, especialmente se este olhar estiver voltado a neurose narcísica meio a um contexto imerso em restrições, isolamento e morte? Para dar conta destas indagações, o presente trabalho pretende mediante revisão bibliográfica, retomar o conceito de trauma, bem como as suas manifestações e suas implicações junto às questões do narcisismo, sobretudo durante esse período pandêmico. Os sujeitos foram convocados a enfrentar o medo, a angústia, bem como invocar seus fantasmas e reviver complexos infantis, com seus desdobramentos e suas neuroses.
Abstract: Among the main psychic structures of psychoanalysis, the neurotic structure is constituted with complexity and differs from different destinations given the traumatic experience lived by the individual, as well as the different levels of each neurosis. Thinking about the characteristics of the neurotic structure, the need arose to re-think narcissistic neurosis in a more detailed way, especially because it was based on the reality experienced in the current global context. This context illustrates a pandemic moment, in which each subject lives the experience of being facing the possibility of contagion and the consequences suffered by him from this environment. This reality has led to the questioning, how can we, today, think of the neurotic structure as a hermetic structure, especially if this look is turned to narcissistic neurosis amid a context immersed in restrictions, isolation and death? In order to deal with these questions, the present work intends, by means of bibliographic review, to resume the concept of trauma, as well as its manifestations and its issues with narcissism, especially during this pandemic period. The subjects were called upon to face fear, anguish, as well as inoke their ghosts and relive children, with their unfolding and neuroses.

Keywords: Neurosis; Trauma; Pandemic.

Palavras-chave: Neurose; Trauma; Pandemia.

\footnotetext{
1 Especialista em Avaliação Psicológica pela Pontifícia Universidade Católica do Rio Grande do Sul (PUC-RS). Psicóloga. E-mail: elismuria@gmail.com

2 Pós Graduanda em Psicanálise pela Universidade do Vale do Rio dos Sinos (UNISINOS). Psicóloga. E-mail: vitoria.justin@hotmail.com

3 Bacharel em Psicologia pelo Centro Universitário Cenecista de Osório (UNICNEC). E-mail: iqueb2@gmail.com

${ }^{4}$ Estudante de Psicologia no Centro Universitário Cenecista de Osório (UNICNEC). E-mail: biellicoski@gmail.com

5 Psicóloga Clínica. Assessoria de Psicologia Escolar em Escola de Educação Infantil. E-mail: kamilymoro@hotmail.com
} 


\section{Introdução}

Dentre as principais estruturas psíquicas da psicanálise, a estrutura neurótica se constitui com complexidade e se difere a partir dos diferentes destinos dados a experiência traumática vivida pelo indivíduo, bem como os diferentes níveis de cada neurose. Pensando nas características da estrutura neurótica, surgiu a necessidade de repensar a neurose narcísica, especialmente pelo fato desta ter sido pautada sobre a realidade vivida pela humanidade no contexto global atual. Contexto este que ilustra um momento de pandemia, no qual cada sujeito vive a experiência de estar frente à possibilidade de contágio e às consequências sofridas por ele a partir deste ambiente. Se faz preciso, na atualidade, pensar a estrutura neurótica, como uma estrutura complexa e passível a sofrimentos e angústias, especialmente se este olhar estiver voltado a neurose narcísica meio a um contexto social imerso em restrições, isolamento e morte.

Posto isto, o presente trabalho pretende, através de revisão bibliográfica, abrandar a estas inquietações iniciais que permeiam a todos, tal como trazer a discussão aquilo que é da ordem do psíquico. Neste sentido, percorrer 0 trajeto pulsional para melhor compreender a origem das neuroses será, como referido anteriormente, o ponto de partida, e posteriormente avançar por seus conceitos e especificidades. Perpassar, a partir desta trajetória, pelo conceito de trauma e narcisismo, culminando assim na relação do sujeito neurótico, mais especificamente na estrutura narcisista, sob a ótica de um sujeito que na atualidade está submetido a lidar com os atravessamentos e cerceamentos a ele impostos, e inevitavelmente, de seus efeitos.

É imperativo ainda citar, o fato de que, possivelmente nosso objeto de reflexão acerca do tema proposto, esteja visível apenas em sua superfície, já que ele transcorre no momento presente, está em alto nível global. Eque, seus desdobramentos e efeitos serão alvo de estudos por um tempo ainda indefinido, e quem sabe, sua indefinição deixe de ser quando o estado pandêmico vier a se tornar uma página a mais na história da humanidade.

\section{Método}

A elaboração deste artigo se deu por meio de uma pesquisa de cunho qualitativo, realizando sua construção com base nas leituras realizadas pelo comitê de estudos em psicanálise do núcleo litoral Norte da Sociedade de Psicologia do Rio Grande do Sul, foram selecionados para ser utilizados nesse artigos livros, artigos e uma dissertação. Textos os quais davam foco ao objetivo central deste artigo que era o de realizar uma releitura da teoria freudiana sobre as neuroses em contraste com os possíveis efeitos que permeiam o cenário contemporâneo no qual se experiencia a pandemia de COVID-19.

Com base nisso foram utilizadas obras clássicas de Sigmund Freud como por exemplo Conferências introdutórias à psicanálise (1916[1917]-2014) e Neurose, psicose e perversão (1856[1939]-2019), bem como o Vocabulário de psicanálise (1970-2001) de Jean Laplanche e Jean Pontalis, para além de autores contemporâneos como Christian Dunker com sua obra A arte da quarentena para principiantes (2020) e dentre outros textos, como 0 artigo: Saúde mental nos tempos de pandemia: uma releitura dos afetos e da pulsão de morte em freud (2020) escrito pela psicanalista e mestre em psicologia Luzia de Oliveira.

Fundamentados neste material literário para além das obras não supracitadas mas presentes no corpo deste artigo, se deu então uma revisão da literatura do tipo narrativa, a qual segundo Rother(2007): "0s artigos de revisão narrativa são publicações amplas apropriadas para descrever e discutir o desenvolvimento ou o'estado da arte' de um determinado assunto, sob ponto de vista teórico ou conceitual". Apesar de tradicionalmente tal metodologia apresentar um nível de evidência relativamente baixa, consideramos que tais revisões podem contribuir para fomentar o debate de determinadas temáticas em um curto espaço de tempo permitindo assim atualizações constantes justificando assim a sua escolha para esta pesquisa.

\section{$A(s)$ neurose(s) e seu(s) destino(s)}

Se pode dizer que, o interesse de Freud pelo entendimento das neuroses, se deu a partir da observação de pacientes histéricas ainda no século XIX, e que seu artigo A hereditariedade e a etiologia das neuroses de 1896, sustentou os inícios da construção da psicanálise. Para Freud (1925[1923]-2011, p. 177), a neurose seria o resultado de um conflito entre o eu e o isso, no qual o papel do eu se configura no gerenciamento entre o mundo exterior e o isso, e na satisfação de ambas instâncias psíquicas. No início deste conflito, o eu em relação às demandas vindas da realidade, se nega a ceder às exigências pulsionais do isso de forma motora, ou de se impor a elas. Nessa relação, segundo Freud, há uma inclinação normal à defesa, ou seja, há uma propensão contrária sob a energia psíquica a fim de que se produza desprazer. Em sua defesa, o eu se utiliza do mecanismo da repressão, no qual o desejo reprimido se serve de um substituto que o represente, assim constituindo uma formação de compromisso, ou melhor, o sintoma, que por sua vez, se impõe ao eu. A formação do sintoma se dá através do retorno de um conteúdo outrora recalcado, no qual o recalque falha e a energia excedente gerada pela representação original escapa, dando nova composição a representação primeva com a finalidade de satisfazer tal pulsão e a ambas instâncias psíquicas. Se faz imprescindível citar a afirmação de Freud, ainda no texto sobre a etiologia das neuroses, que cada uma delas, tem como causa imediata, uma perturbação específica da economia psíquica e que têm como fonte comum a vida sexual do sujeito, sejam perturbações do momento de vida atual ou de fatos importantes de sua vida passada.

Dessa forma, podemos afirmar que os diferentes tipos de neurose surgem com um objetivo comum, o de substituir uma forma de satisfação perigosa e inaceitável por um sofrimento consciente a nível de um sintoma, mas inconsciente no que se refere a sua origem primeira; e que eles podem ser diferenciados de acordo com os mecanismos utilizados por estes na transformação do excesso advindo da experiência traumática original. Em outras palavras, estas são determinadas, "pelo modo como o indivíduo perfaz o desenvolvimento da função sexual, ou, como dizemos, pelas fixações que sua libido experimentou no curso de seu desenvolvimento" (Freud, 1917-2010, p. 181).

Como desfecho, se configuram as neuroses, resultado da fixação do sujeito a uma etapa específica do seu desenvolvimento libidinal. Laplanche e Pontalis (2001) apontam na mesma direção, e referem que a neurose pode ser definida como uma "afecção psicogênica em que os sintomas são a expressão simbólica de um conflito psíquico que tem raízes na história infantil do sujeito e constitui compromisso entre o desejo e defesa" (Laplanche e Pontalis, 2001, p. 296).

Sobre as neuroses de defesa, Freud discorreu que há uma identidade entre elas, nas quais seus estados psíquicos afetivos provêm de um conflito, de diferentes e variadas naturezas, e que, estes por sua vez, não levam a 
nenhuma resolução. Seu resultado é o adoecimento, após o retorno das representações recalcadas, que são distintas entre si pelo caráter e modo como o recalcamento foi consumado.

Dentre elas, a neurose obsessiva-compulsiva foi a que Freud examinou melhor. Ela refere-se ao sofrimento consciente no pensamento em que a satisfação se encontra deslocada, nela a carga afetiva é separada de sua ideia original e é religada a novas representações aceitáveis. No caso da neurose fóbica, por outro lado, o prazer intolerável é projetado para fora do sujeito sendo solidificado em algum elemento do ambiente externo o qual passa a ser visto como um objeto ameaçador. Atualmente, as neuroses obsessivas são classificadas nos manuais de psiquiatria e psicologia como Transtorno Obsessivo Compulsivo (TOC), e/ou compõem o quadro dos Transtornos de Ansiedade. Assim como, as neuroses obsessivas, a agorafobia e fobia social entre outras, se encontram com diferentes nomes no meio psiquiátrico.

No que concerne, a neurose histérica, o excesso é convertido em um sofrimento corporal, chamando atenção o valor simbólico desta afecção. 0 conflito psíquico se simboliza em sintomas corporais diversos, sejam eles de maior intensidade ou mais duradouros, como crise emocional e teatralidade, bem como anestesias e paralisias histéricas. A neurose traumática, por sua vez, tem como causa atuante o trauma psíquico, que segundo Freud é: "qualquer experiência que possa evocar afetos aflitivos - tais como os de susto, angústia, vergonha ou dor física - pode atuar como um trauma dessa natureza; e o fato de isso acontecer de verdade depende, naturalmente, da suscetibilidade da pessoa afetada" (Freud, 1987[1893], p. 43).

Seus sintomas resultam de uma fixação no momento do acidente traumático, que por sua vez passará a ser reeditado, transportando repetidamente o sujeito à situação traumática, como se fosse impossível superá-la. Outra possível classificação trazida por Freud é a das neuroses atuais vistas como uma interferência química que leva aos impedimentos da satisfação sexual na vida atual do sujeito, tal termo foi cada vez menos utilizado pelo autor em sua obra. Estas eram inicialmente divididas em três subtipos: neurastenia, neuroses de angústia e hipocondria.

\section{Trauma e seus efeitos}

Examinar o caminho das neuroses em Freud proporcionou adentrar as questões relacionadas ao trauma, e as examinar no cenário atual, este conturbado, propiciado pela pandemia de Covid-19, cheio de angústias e incertezas. Assim, torna-se necessário retomar a elaboração do conceito de trauma bem como as suas manifestações na atualidade, visando obter uma maior compreensão acerca da temática do traumático e suas implicações junto às questões do narcisismo sobretudo durante esse período pandêmico.

Para isso retomando os pensamentos de Freud (1917[1916]-2014) sobre essa questão, onde o autor traz por meio do texto A fixação no trauma - 0 inconsciente (Freud, 1917[1916]-2014, pp. 297-310) a ideia que de 0 "traumático"não tem outro significado senão o econômico, uma vez que afeta permanentemente o gerenciamento de energia disponível, de forma que se pode interpretar que a experiência traumática seria aquela que em um breve momento ou espaço de tempo, seria capaz de propiciar um enorme estímulo, a ponto que sua elaboração não poderia mais ser realizada pelos meios normais.

Segundo Laplanche e Pontalis (2001) é por meio da psicanálise contemporânea que se retoma esse termo transpondo-o por três significações implicadas no psiquismo: um choque violento, uma ruptura e consequências sobre o conjunto organizacional. Acabando por considerar que a constituição do psiquismo visto por Freud (1917[1916] - 2014), seria oriundo desses resquícios energéticos do fluxo excedente de excitação, gerados por meio da proibição ou renúncia das satisfações pulsionais de forma que o pensamento e o plano psíquico nasceriam da impossibilidade de descarga das excitações, deslocadas então, para outros fins que não a satisfação do princípio do prazer.

De forma congruente aos autores supracitado, Marques (2006) aponta que a manifestação do traumático pode ser considerado como um sinal de urgência para que ocorra um remanejamento do narcisismo, visto que a forma que a perda objetal pode interferir num certo circuito estabelecido por investimentos pulsionais, Ihe atribuindo um carácter por vezes melancólico a manifestação do trauma. Sendo então necessário uma ressignificação desse deslocamento do investimento libidinal, mantido na virtualidade de preservação ideativa do objeto que o sujeito, visando redirecionar essa energia narcísica para o eu propriamente dito.

Alinhado a esse pensamento Mello (2020) por meio da entrevista Luto napandemia Covid-19 para a revista PsicoFAE aponta que os desdobramentos traumáticos vivenciados na atualidade podem ser vistos como um estado de luto. Uma vez que este momento de total incerteza sobre vida e morte, está permeado por tantas outras crises pessoais e coletivas, onde o sujeito se depara com a culpa presente na perda narcísica-objetal. Cabe diferenciar brevemente as características específicas do luto e da melancolia, pois ambos têm algo em comum, a perda de um objeto. Admitir essa perda fálica, acaba por ser a renúncia que os neuróticos passam a vida toda se negando a realizar (Mello, 2020).

Freud em Luto e Melancolia (1917 [1915] - 2010), diz que o trabalho de luto é um processo psíquico normal, e que mesmo que a perda do objeto amado seja motivo de dor e sofrimento, isto é algo esperado, e que, posteriormente e gradativamente irá ocorrer 0 abandono pelo enlutado, de seus desejos em relação ao morto, dando assim, lugar a realidade. № caso dos melancólicos, em contradição aos enlutados, há a impossibilidade de reconhecer tanto a natureza do objeto perdido quanto a origem da perda. $E$ mesmo que saibam falar sobre quem perderam, não conseguem dizer o que foi perdido junto com o objeto.

\section{Neurose e narcisismo}

Em Introdução ao Narcisismo: ensaios sobre metapsicologia e outros textos (1916 [1914] - 2010), Freud refere que observou na clínica com neuróticos muito das características narcísicas na condutas destes pacientes, e que, por sua vez, estas características poderiam se "apresentar de modo bem mais intenso e exigir um lugar no desenvolvimento sexual regular do ser humano". Ele quis dizer que, esta porção narcísica serviria como "complemento libidinal do egoísmo de autopreservação", e que estaria presente em cada indivíduo. É importante assinalar aqui, que neste texto, Freud traz à discussão a teoria da libido agora voltada para o eu, o que anteriormente estava focada na objetalidade.

No entanto, foi somente em 1914 que ele atribui o narcisismo como premissa para a formação do eu, referindo que há um narcisismo primário e normal, alicerçado sobre a fase intermediária entre 0 autoerotismo e a escolha objetal, essencial a formação do eu. Há um investimento da libido, que inicialmente está sobre o eu e posteriormente será direcionada aos 
objetos, no entanto, Freud afirma que, a libido permanece presente no eu, essencialmente no narcisismo secundário. A partir desta descoberta, ele assinala que um narcisismo primário pode interferir de forma dominante em um indivíduo, no que se refere às suas escolhas de objeto. Ainda no texto Introdução ao Narcisismo, é inserida a distinção entre pulsões sexuais e libido do eu, representando a dupla função do indivíduo, tal qual a confirmação de que o narcisismo é significativo em seu desenvolvimento normal.

Posteriormente, ao longo do desenvolvimento da teoria das neuroses narcísicas, a teoria freudiana busca elaborar um representante para a melancolia, neste sentido, com base em seus textos anteriores, Freud aponta à importância de duas instâncias psíquicas, a do supereu com a função da proibição e a consciência moral que, por meio do ideal de eu, avalia as pretensões do eu. Subsequentemente, Freud cita que a melancolia tem como procedência, uma perda objetal e uma identificação objetal narcísica, bem como autocrítica rígida, decorrentes da ambivalência em relação a objeto, por sua vez perdido.

Na melancolia, o empobrecimento do investimento no objeto é mensurado a partir da extensão do investimento no eu, no mesmo sentido ele refere que a ambivalência em relação ao objeto, faz com que haja uma retração da libido dos objetos, voltando ao eu. Referimos a "melancolia" como meio de dissertar acerca da neurose narcísica. Vale assinalar ainda, no grupo das neuroses narcísicas, a paranoia com sua concepção voltada a regressão à uma escolha homossexual e narcisista de objeto, e a demência precoce com sua gênese voltada ao autoerotismo (Freud, 1916 [1914] - 2010).

Para a psicanálise, existem impedimentos importantes para a clínica com este tipo de paciente, pois existe uma linha tênue entre ele e o paciente com depressão, é necessário questionar o manejo da transferência com estes pacientes, e aprofundar meios de interpretação para os sintomas melancólicos; levando em conta a dificuldade de enlace na construção da neurose de transferência, na neurose narcísica. Na neurose narcísica, o que ficou evidente foi a ausência da inscrição da perda do objeto, que deveria ter sido constituída no narcisismo primário, houve uma falha nesta simbolização, o que demonstra que o objeto perdido sequer teve a oportunidade de ser inscrito pelo paciente. 0 que segundo Freud, está relacionado a imagem ideal de si no narcisismo primário, que conforme referido acima, fracassou.

Neste sentido, estas afecções denotam aos seus algozes, uma barreira capaz de impedir o trabalho de luto, e o indivíduo por sua vez, fal ha na elaboração da perda, já que sua escolha inicial de objeto foi uma escolha narcísica, e neste contexto, quando há um investimento no objeto e este encontra uma objeção, retorna para 0 eu.

Podemos dizer que o eu encontra-se perdido, impossibilitado de transformação, sem recursos de investir nos objetos externos, condição que o mobiliza a pensar o lugar que a psicanálise pode prestar a este indivíduo que, por sua vez, se sente inundado e ameaçado pelo sentimento de vazio. Nesta posição, e com estas características, ele joga para si toda a repressão, em consequência de ter desistido de sua posição desejante.

Abarcando o pensamento psicanalítico acerca da etiologia e manejo das neuroses narcísicas, especificamente no contexto de pandemia atual, há uma validação à complexidade de pensar este indivíduo e esta relação, já que em sua essência a neurose narcísica é profunda. 0 contexto de morte evidenciado pela pandemia, joga por inteiro este indivíduo, no mais profundo vazio, desamparo e necessidade de amor, revelando que, seu investimento está voltado ao ideal de eu, como meio de gratificar, satisfazer o que adentra em seu mundo interno através do mundo externo. Aqui emerge a imposição, na neurose narcísica, em manter a satisfação sentida no narcisismo primário, onde o eu era seu próprio ideal.

A pandemia, em sua imperiosa ordem e discurso de morte, apresenta à este indivíduo suas falhas, seus temores e imperfeições, algo que o fere profundamente, visto que na neurose narcísica, a desesperança revela o modo como este encara a vida, sem passado, presente ou futuro, estando imerso em perda e vazio. Realidade explícita pela pandemia, na qual o futuro, neste momento, está à mercê do desejo do tempo, tempo de espera, de angústia, incerteza e sofrimento, ambos conotados pela iminência da morte, que ocupa espaço no sujeito, em seu mundo externo e interno.

0 que traz a reflexão, os efeitos desses traumas sobre os traumas já vivenciados, especialmente na neurose narcísica, sendo assim, como Freud mencionou, as neuroses aparecem misturadas, e cabe ao analista observar o fato de que, uma neurose atual pode estar inserida em uma psiconeurose. Quer dizer que, uma neurose atual é como um grão de areia no centro da pérola, alusão usada por ele para exemplificar a ideia de que o núcleo do sintoma psiconeurótico é formado por um sintoma somático. 0 analista deve estar apto a tentar diferenciar a essência da neurose, se esta tem a ver com a história sexual infantil do paciente ou se está relacionada com uma afecção sexual atual do mesmo.

Se, o contexto atual de morte, como ponte ao traumático, invade e se declara como uma ameaça ao eu, não há outra alternativa no manejo, no que se refere às neuroses narcísicas, a não ser o de construir um campo transferencial/ contra transferencial continente, a fim de poder dar conta da força do pulsional, ainda que Freud tenha mencionado o quão impenetráveis podem vir a ser estes pacientes durante seu tratamento. No processo analítico, não somente em relação às neuroses mas, a toda e qualquer forma de sofrimento psíquico, é urgente trabalhar as implicações deste traumático inscrito pela pandemia, e se aplica à psicanálise tentar estar um passo frente, como exigência ao avanço, no que se refere a compreensão e aprofundamento no campo das vivências dos sujeitos, pelo viés do tempo lógico da inscrição dos possíveis traumas causado pela pandemia global.

\section{Atravessamentos da pandemia na estrutura neurótica}

Vivemos o que Dunker (2020) chama de gramática da polarização. De um lado precisamos preservar a vida humana, sendo assim, nos foi imposto manter 0 isolamento social evitando o contato com nossos semelhantes, cumprindo regras e normas comuns a todos, preservando a vida e evitando a morte. Por outro lado, no entanto, precisamos manter a economia funcionando, resolução que abre espaço para uma discussão social importante, que irá acarretar, dentre um universo de perdas, prejuízos financeiros, psíquicos e a morte, pela via do corpo e ou pela via psíquica ou pulsional.

A pandemia do Novo Coronavírus é democrática, atinge a todos sem distinção, independente da raça, idade, credo, classe política ou social, ela é letal e ameaça a todos. É uma peste que não ataca apenas os corpos, mas identidades, sentimentos de pertença e de filiação a uma determinada ordem. Os sujeitos são convocados a enfrentar o medo e fazer frente a angústia, o problema começa quando o medo do que vem de fora se contamina com a angústia interna, "por isso, a doença é o pretexto ideal para ativar preconceitos, invocar fantasmas e revitalizar complexos infantis" (Dunker, 2020, p. 11). 
Além do medo presente na vida das pessoas, a Covid-19 tem elevado o nível de insegurança em todos os aspectos da vida humana, seja na esfera individual ou coletiva, até o funcionamento da sociedade e das relações interpessoais (Faro et. al., 2020). 0 método mais efetivo de prevenção é 0 distanciamento social, medida que impacta significativamente a saúde mental da população podendo deixar sequelas importantes.

Embora os métodos adotados durante quarentena sejam os meios mais eficazes para conter a disseminação do novo Coronavírus, eles podem acarretar alguns estressores causados por exemplo, pelo desejo e pela falta de contato com os amigos e familiares, e do mesmo modo, pelas incertezas em relação a duração do distanciamento. Constata-se também que alguns transtornos mentais podem eclodir pela quarentena, dentre eles o transtorno de ansiedade, depressão e o comportamento suicida (Faro et. al., 2020).

Segundo o Ministério da Saúde [MS] (Brasil, 2020) a mudança repentina nos modos de vida habituais pode contribuir para o desencadeamento de reações e sintomas de estresse, ansiedade e depressão. Adicionalmente, 0 medo de ser acometido por uma doença potencialmente fatal, cuja causa e progressão ainda são pouco conhecidas, afetam o bem-estar psicológico das pessoas. Os sintomas psicológicos são recorrentes em situações que envolvem o distanciamento social, a literatura da área demonstra a presença de solidão, desesperança, angústia, exaustão, irritabilidade, raiva e sensação de abandono. E com isso, maiores chances de ocorrência de distúrbios do sono, abuso de substâncias psicoativas e ideação suicida, bem como, entre outros, 0 agravamento de transtornos mentais já existentes.

0 novo Coronavírus têm gerado grandes desafios diários, não apenas ao que toca aos cuidados externos físicos que visam o extermínio do vírus, mas também ao que diz respeito sobre os constantes desafios emocionais, permeados por diversos sentimentos e sensações que impactam diariamente a vida das pessoas, norteadas por angústias, ansiedades, inseguranças e medos. Tais sentimentos, por vezes não percebidos, são sentidos com uma força significativa e constitutiva ao sujeito, percepção que roga a psicanálise à uma escuta demasiada e sensível a fim de melhor nos aproximarmos das dores psíquicas de cada sujeito.

Nas psiconeuroses, destaca-se a origem conflitiva psíquica, relacionada a sexualidade do sujeito, que possui, na qualidade de seus recursos internos do sintoma, a viabilidade de traduzir seus sofrimentos (Macedo et. al., 2016). É importante ressaltar que, cada indivíduo se depara com seus afetos e externaliza seus recursos psíquicos frente a vivência de um evento que foi traumático e deixou marcas. Tais externalizações serão representadas por atividades diversas, onde cada sujeito precisará ressignificar, no seu tempo, suas conexões do mundo interno para com o mundo externo, o qual hoje é vivenciado pela pandemia do Coronavírus.

A partir das reflexões de Oliveira (2020), diante de uma vivência geradora de muitas angústias, mudanças e tensões, o sujeito pode encontrar importante falta de reconhecimento de si mesmo, em razão de uma estranheza em comportamentos que não eram originários em sua vida. A isto, refere-se que o sujeito pode sentir falta de atenção e energia para a realização de seus compromissos que são de sua trajetória diária, como o seu trabalho, atividades físicas e até mesmo nas relações pessoais. Essas queixas originárias de tantas mudanças, podem gerar incompreensão em muitas pessoas, despertando desconfortos e inquietações que precisam ser trabalhados.

Frente a isto, a escuta psicanalítica pode abrir os possíveis caminhos de acesso ao mundo interno de cada indivíduo de forma significativa, pois estamos todos enquadrados ao mundo social, que tem representação em nossa constituição como sujeitos. Assim, a escuta psicanalítica oferece recursos ao indivíduo a voltar de si mesmo e poder dar vozàs suas construções e desconstruções. Mudança importante na qual o sujeito pode não estar preparado para vivenciar e sentir, mas que está inclusa ao tocante psíquico em decorrência do isolamento social em que se encontra (Oliveira, 2020).

\section{Considerações finais}

0 presente artigo analisou como os sujeitos que padecem pelas neuroses, especialmente pela neurose narcísica, podem sofrer com os efeitos oriundos da pandemia do novo Coronavírus, e almejou saber quais saídas possíveis para enfrentar a realidade deste contexto imerso em restrições, isolamento e morte.

Interpretar o momento atual sob a ótica das neuroses, movimentou ao longo da escrita a imaginação especulativa, e propiciou a relação entre as características da neurose narcísica e a busca incessante na cultura atual de um objeto completo, que dê conta das demandas requeridas e sentidas pelo indivíduo. Busca esta inegável na experiência do narcisismo, e que demarca 0 desejo de satisfação plena e a perda do objeto, como foi alegado ao longo do trabalho. Este enunciado faz alusão às peculiaridades da neurose narcísica, já que dá ao indivíduo a esperança de corresponder com seu ideal de eu as promessas de satisfação vindas de fora, embora, seja uma esperança perdida em um tempo que não chega.

Avaliar a forma como a neurose está inscrita no indivíduo é vital, e pode indicar o modo como ele irá lidar com as adversidades da vida, com maior ou menor prejuízo, de acordo com o nível da sua organização psíquica. Esta avaliação, dentro deste novo contexto, contribui para deduzir que muitos indivíduos não conseguirão suportar toda a pressão e sofrimento, por consequência de suas vulnerabilidades e tendo assim seus sintomas agravados despontando em crises emocionais.

Evidencia-se a urgência de um acompanhamento e tratamento especializados, destinados aos sujeitos que apresentam sofrimentos psíquicos prévios e oriundos das repercussões negativas provocadas pelo distanciamento social da pandemia, visto que tais efeitos podem se prolongar mesmo após 0 fim desta, o que denota a importância de um olhar atento e qualificado dos profissionais de saúde, em especial os da saúde mental, que se ocupam do cuidado dessa população.

Levando em conta, que a cultura e a civilização produzem novas formas de subjetividades e adoecimentos psíquicos, assim como na época de Freud, em que a histeria era dita "doença da época", e passou a mobilizar médicos, psicanalistas, teóricos entre tantos estudiosos, se pode dizer que, este foi 0 intuito desta escrita, buscar uma maior compreensão acerca destes tempos de pandemia. Assim sendo, ficou claro que os questionamentos não sanaram, mas se expandiram em direção a quais efeitos o estado pandêmico atual irá deixar, no que se refere a esta geração ou as futuras.

No entanto, o que se espera, é que as repercussões desta realidade histórica, possam se dar da melhor maneira, dentro da condição de desamparo de cada um, e trazendo a luz os caminhos dos possíveis dos sintomas constituídos durante este tempo. Cabe à psicanálise a escuta de seus pacientes, como fez Freud, para que novas hipóteses se formulem sobre os efeitos da pandemia nos sujeitos, seja em relação ao contexto global, seja em relação às neuroses 
narcísicas. É notório portanto, a produção de mais estudos acerca do tema, uma vez que este é extremamente importante para a compreensão do estudo das neuroses na atualidade.

Portanto, após esta escrita, não há exatidão no que concerne às consequências psíquicas atreladas a Covid-19 em cada sujeito, pois se pensarmos os tempos do trauma, podemos dizer, como mencionado no corpo do texto, que este ainda está sendo inscrito, no aqui e agora de cada um de nós. Este excesso pulsional, sem elaboração, confere a compulsão à repetição o destino factual do traumático, sem representações, sem marcas nítidas que possam redirecionar o que é da ordem de si mesmo, frente a sua interdição que se impõem pelo prenúncio de morte.

Se faz necessário que outros estudos acerca do tema sejam realizados em virtude da complexidade e da importância da temática abordada para as áreas das ciências humanas. Compete à psicanálise inquirir, repetir, agir, dizer incessantemente sobre os desafios e limites frente a clínica psicanalítica, e as inúmeras formas de sofrimentos da psique humana, dado que nela habitam a vida e morte, possibilitando assim aos sujeitos repensar sua história de vida para que haja outros caminhos em direção ao devir do desejo e posteriormente outras possibilidades de vida.

\section{Referências}

Brasil. Ministério da Saúde (2020). Saúde Mental e Atenção Psicossocial na Pandemia COVID-19: Um guia para gestores. Fiocruz: Ministério da Saúde. Disponível em https://www.fiocruzbrasilia.fiocruz.br/wp-content/ uploads/2020/04/Sa\%c3\%bade-Mental-e-Aten\%c3\%a7\%c3\%a30-Psicossocial-na-Pandemia-Covid-19-recomenda\%c3\%a7\%c3\%b5es-para-gestores.pdf

Dunker, C. I. L (2020). A arte da quarentena para principiantes. São Paulo: Boitempo.

Faro, A., Bahiano, M. A., Nakano, T. C., Reis, C., Silva, B. F. P., Vitti, L. S (2020). COVID-19 e saúde mental: a emergência do cuidado. Estudos de Psicologia (Campinas), 37, e200074. Epub June 01, 2020. Disponível em: https:// doi.org/10.1590/1982-0275202037e200074.

Freud, S. (1893[1899]-1996) Primeiras publicações psicanalíticas: A hereditariedade e a etiologia das neuroses. Obras completas. vol. 03, São Paulo: Imago.

Freud, S. (1856[1939]-2019). Neurose, psicose e perversão. In Obras incompletas de Sigmund Freud, vol. 5, Belo Horizonte: Autêntica Editora.

Freud, S. (1916 [1914]-2010) Introdução ao narcisismo: ensaios de metapsicologia e outros textos. Obras completas, vol. 12, São Paulo: Companhia das Letras.

Freud, S. (1917 [1915]-2010) Luto e Melancolia, In Introdução ao narcisismo: ensaios de metapsicologia e outros textos. Obras completas, vol. 12, São Paulo: Companhia das Letras.

Freud, S. (1916[1917]-2014) Conferências introdutórias à psicanálise (pp. 297-310). Obras completas vol. 11, São Paulo: Companhia das Letras.

Freud, S. (1917[1916]-2014) A fixação no trauma - O inconsciente, In Obras completas vol. 14, São Paulo: Companhia das Letras.

Freud, S. (1925[1923]-2011). Neurose e Psicose, In Obras completas vol. 16, 0 Eu e i ld, "Autobiografia" e outros textos (pp. 176-183). São Paulo: Companhia das Letras.

Laplanche, J. \& Pontalis, J (2001). Vocabulário de psicanálise (4a ed), D. Lagache (Dir). São Paulo.

Macedo, K. M., Eurema, G. M., Mohr, A., Sissi, V. C., Vivan, S. B., Veras, J. F, Hornstein, L. Krug J. S (2016). Neurose Leituras Psicanalíticas (4a ed), Porto Alegre: PUCRS.
Marques, S. T. (2016, fev.) Quando a prótese não é uma muleta - um estudo psicanalítico sobre a experiência de amputação e reconstrução do corpo. Dissertação (Mestrado em Psicologia Clínica) Pontifícia Universidade Católica do Rio de Janeiro. Disponível em https://www.maxwell.vrac. puc-rio.br/colecao.php?strSecao=resultado\&nrSeq=8567@1

Mello, R. (2020). Luto na pandemia covid-19. Revista PsicoFAE: Pluralidades em Saúde Mental, [S.I.], v. 9, n. 1, jul. 2020. ISSN 2447-1798. Disponível em https://revistapsicofae.fae.edu/psico/article/view/289/171

Oliveira, de C., L. (2020). Saúde Mental nos Tempos de Pandemia: uma releitura dos afetos e da pulsão de morte em Freud. Paulo, Brasil: Martins Fontes. Disponível em https://revistapsicofae.fae.edu/psico/article/ viewFile/290/172.

Rother ET .(2007). Revisão sistemática X revisão narrativa. Acta paul. Enferm; 20(2):v-vi Disponível em .https://www.scielo.br/pdf/ape/v20n2/ a01v20n2.pdf

Soares, R. L. (2014), A identificação e o narcisismo na melancolia: reflexões a partir da obra freudiana. 2014. 134f. Tese (Doutorado em Psicologia Clínica e Cultura) - Universidade de Brasília, Brasília, 2014. Disponível em https:// repositorio.unb.br/handle/10482/17908. 